\title{
Quantifying the ex-post causal impact of differential pricing on commuter trip scheduling in Hong Kong
}

\author{
Anupriya*, Daniel J. Graham, Daniel Hörcher, Richard J. Anderson, Prateek Bansal \\ Transport Strategy Centre, Department of Civil and Environmental Engineering, \\ Imperial College London, South Kensington Campus, London SW7 $2 A Z$.
}

\begin{abstract}
This paper quantifies the causal impact of differential pricing on the trip-scheduling of regular commuters using the Mass Transit Railway (MTR) in Hong Kong. It does so by applying a difference-in-difference (DID) method to large scale smart card data before and after the introduction of the Early Bird Discount (EBD) pricing intervention. We find statistically significant but small effects of the EBD in the form of earlier departure times. Leveraging the granularity of the data, we also allow for the treatment effect to vary over observed travel characteristics. Our empirical results suggest that fares and crowding are the key determinants of commuter responsiveness to the EBD policy.
\end{abstract}

Keywords: public transport pricing, peak spreading, causal analysis, smart card data, difference-in-difference, trip scheduling

Declarations of interest: None.

Funding: This research did not receive any specific grant from funding agencies in the public, commercial, or not-for-profit sectors.

${ }^{*}$ Corresponding author. Email address: anupriya15@imperial.ac.uk 


\section{Introduction}

Rapid urbanisation has led to a tremendous growth in peak commute by public transit globally $^{1}$. The resulting overcrowding can degrade service quality, affect reliability and increase the adverse impact of service disruptions in transit systems (Preston et al., 2009). To address overcrowding problems in public transit services, operators may adopt pricing policies as demand management measures to influence passenger behaviour.

In a dynamic context such as the morning commuting problem, pricing might affect passenger behaviour in at least two ways: (i) it regulates aggregate ridership as lower fares induce demand, and (ii) it also influences passengers' trip scheduling decisions. The quantitative measurement of the first effect is a regular exercise in transport science: the sensitivity of ridership to fare levels has been documented extensively in the form of aggregate demand elasticities (for instance, see Paulley et al., 2006; Graham et al., 2009; Wardman, 2014). However, much less is known about the magnitude of the second impact, primarily due to the scarcity of reliable disaggregate data on individual trip scheduling in areas where differential pricing interventions have been implemented. These rescheduling elasticities are important to estimate because they can be used to calibrate theoretical models of an optimal dynamic fare scheme, as discussed in studies such as De Palma et al. (2015) and De Palma et al. (2017). We contribute to this line of research by quantifying the causal impact of a pricing policy on trip scheduling in isolation.

We study the impact of the Early Bird Discount (EBD), a differential pricing policy introduced by the Mass Transit Railway (MTR) on September 1, 2014. The policy allows MTR users to avail a 25 percent fare incentive if they exit at the twenty-nine designated stations in the central business district from 07:15 to 08:15. Figure 1 shows the arrival rates of trips in 15-minute intervals at the discounted stations in the MTR network on a typical workday in October 2013 and October 2014. This comparison suggests three potential effects of the EBD on demand. First, we observe a reduction in demand during the peak shoulder hours, that is $08: 15$ to $08: 45$. This change in travel pattern of existing commuters suggests that they may alter their trip schedules. Second, we observe a greater increase in demand (disproportionate to the decrease in demand in the peak shoulder) during the discounted period, that is $07: 15$ to $08: 15$, which suggests that induced demand

\footnotetext{
${ }^{1}$ The UITP Statistics Brief, 'Urban Public Transport in the 21st Century': http://www.uitp.org/urban-public-transport-21st-century.
} 
may emerge within the discounted period to take advantage of lower fares. Third, we observe an even greater increase in demand during the peak-of-the-peak, that is 08:45 to 09:15, perhaps because the expectation for lower crowding induces demand in the peak as well. Whereas the first effect is the rescheduling effect, the remaining two can be classified as the induced demand effects of the EBD. In this analysis, we focus on quantifying the causal effect of the EBD on the trip scheduling behaviour of regular commuters (that is, the first effect) because this is the primal reason why the policy may reduce peak-crowding levels.

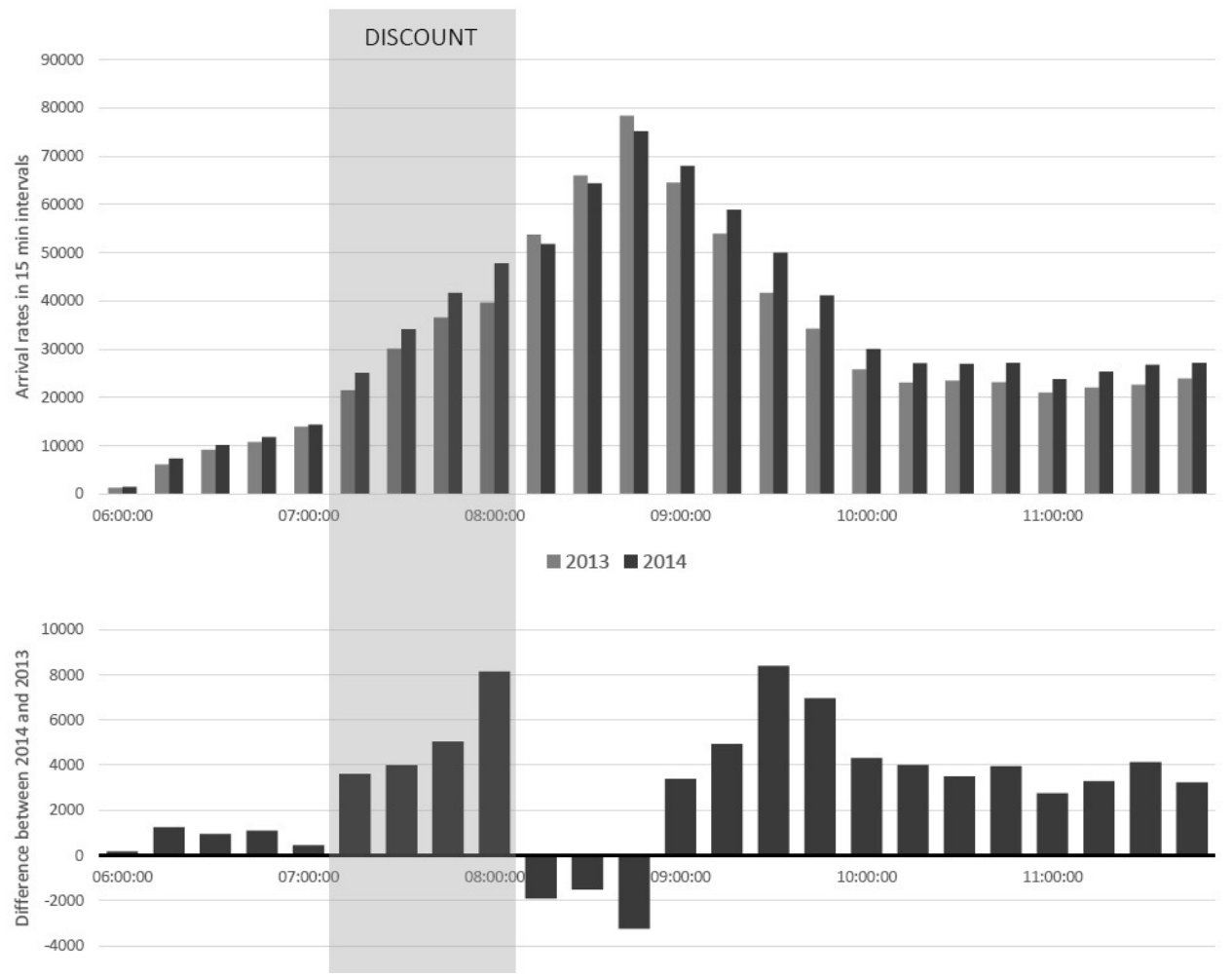

Figure 1: Arrival rates of trips per 15 minutes at the discounted stations in the MTR network on a typical workday in October 2013 and October 2014.

Numerous ex-ante travel surveys have been carried out in the past to understand the willingness of existing users to shift their trip schedules at different levels of prepeak travel discounts (Henn et al., 2011). Recent studies have also capitalised on the capability of large-scale data to study the impact of similar policy interventions in public transport. Zou et al. (2019) and Halvorsen et al. (2016) use smart card data to study the impact of an off-peak fare discount on transit demand in Beijing and Hong Kong respectively. These studies compare travel patterns of passengers before and after the policy to quantify the effects of the intervention. However, the impact estimated in these 
studies may suffer from confounding biases, which emerge due to temporal trends. For example, the difference in arrival rates between 2013 and 2014, as observed in Figure 1, may not be solely due to the EBD because there may be an intrinsic (temporal) increase in demand over years. Moreover, other effects unrelated to the intervention such as weather and service disruptions may further exacerbate the issue of confounding bias.

Thus, the estimates derived from a simple before-after comparison of demand, as obtained in Zou et al. (2019) and Halvorsen et al. (2016), do not reflect the true policy effect. We address this gap in the literature by adopting a causal inference approach, a difference-in-difference (DID) model, with smart card data to estimate the trip scheduling response of Hong Kong MTR commuters to the EBD. DID facilitates the unbiased estimation of the causal effect by handling the above-mentioned sources of confounding bias.

We first estimate the impact of EBD at the network (that is, aggregate) level. We find small, however, statistically significant aggregate-level effect of the policy. The granularity of smart card data also enables us to estimate the impact of policy for each origindestination (OD) pair (that is, disaggregate level). We observe substantial variation in average treatment effect across OD pairs. To identify the factors that influence the responsiveness of MTR commuters to the $\mathrm{EBD}$, we allow the treatment effect to vary with observed pre-treatment OD-level travel characteristics (e.g., travel costs and crowding levels) in another DID specification. These estimates of heterogeneous policy effects provide insights into how transit operators can better target the less responsive user groups and make such policies more effective.

The remaining of this paper is organised as follows. Section 2 provides a contextual review of the literature. Section 3 describes the DID model and smart card data. Section 4 presents the DID estimates of the trip scheduling impact of EBD at aggregate and disaggregate level. Section 5 summarises the key results of another DID specification which determines the sources of heterogeneity in treatment effect across OD pairs. Conclusions and policy implications are drawn in the final section.

\section{Literature Review}

A large volume of research exploring the responsiveness of rail users to different pricing policies has been conducted over the past few decades. Several variants of EBD policies 
have been implemented in cities like Melbourne, Singapore and Hong Kong. Extensive reviews can be found in Halvorsen (2015) and Liu and Charles (2013). The key findings of previous studies are summarised in Table 1. In this section, we review previous surveyand smart card-based studies, followed by highlighting research gaps in the literature and summarising contributions of this study.

\subsection{Survey Based Studies}

Most of the previous studies have used surveys to assess overall impact of EBD policies in terms of trip scheduling flexibility of users and factors that determine this flexibility (see Table 2 for summary). The literature suggests that the effectiveness of inter-peak to peak fare differentials in reducing peak loads is very limited. For instance, the UK's Strategic Rail Authority found that 10-30 percent discounts on off-peak fares will not cause any substantial reductions in peak loading and suggested higher peak-to-off-peak fare differentials to achieve more substantial shifts (as mentioned in Halvorsen (2015); Henn et al. (2010) and other references therein). A stated preference study of Sydney rail commuters shows that 19 percent of them were willing to travel 30 minutes earlier and 13 percent later for a 30 percent discounted fare (Henn et al., 2011). Whelan and Johnson (2004) recommended a peak surcharge combined with an off-peak discount. However, such peak surcharges may accompany mode shifts to private cars or result in social exclusiveness (Henn et al., 2010).

\subsection{Studies based on smart card data}

Although survey data contain detailed information about various aspects of a user's activity pattern, survey-based assessment of policy impacts can be methodologically challenging and both resource and time-intensive. The potential drawbacks are well known, which include observing limited pool of respondents, reporting errors, fatigue effects amongst respondents, and attrition bias, among many others (Goulet-Langlois et al., 2016; Long and Thill, 2015). Large-scale smart card data have emerged as a promising alternative to measure the impact of policy interventions in detail. Smart card data facilitates a better understanding of changes in user behaviour as these datasets provide access to population-level longitudinal data (Agard et al., 2006; Bagchi and White, 2005). 
Table 1: Review of the key empirical studies quantifying the impact of pre-peak travel discount policies.

\begin{tabular}{|c|c|c|c|c|c|}
\hline Study & Area of study & Type and magnitude of pricing policy & Empirical method used & $\begin{array}{l}\text { Time horizon of the } \\
\text { analysis }\end{array}$ & The estimated effect on demand \\
\hline $\begin{array}{l}\text { Halvorsen et al. } \\
(2019,2016)\end{array}$ & Hong Kong MTR & $\begin{array}{l}25 \% \text { discount on trips terminating be- } \\
\text { fore } 8.15 \text { a.m. at designated MTR sta- } \\
\text { tions on weekdays. }\end{array}$ & $\begin{array}{l}\text { Clustering of passengers fol- } \\
\text { lowed by a before-after com- } \\
\text { parison of passenger flows } \\
\text { data. }\end{array}$ & $\begin{array}{l}2 \text { months post- } \\
\text { implementation of } \\
\text { the discount }\end{array}$ & $\begin{array}{l}\text { The proportion of eligible peak hour trips between } \\
\text { 7:00-9:30 a.m. decreased by about } 3 \% \text {, links with } \\
\text { higher levels of crowding showed larger changes. Com- } \\
\text { muters showed the highest response rates. }\end{array}$ \\
\hline $\begin{array}{l}\text { Ma et al. } \\
(2019)\end{array}$ & Hong Kong MTR & $\begin{array}{l}25 \% \text { discount on trips terminating be- } \\
\text { fore } 8.15 \text { a.m. at designated MTR sta- } \\
\text { tions on weekdays. }\end{array}$ & $\begin{array}{l}\text { Clustering of passengers fol- } \\
\text { lowed by a before-after com- } \\
\text { parison of passenger flows } \\
\text { data. }\end{array}$ & $\begin{array}{l}2 \text { months and } \\
1 \text { year post- } \\
\text { implementation of } \\
\text { the discount }\end{array}$ & $\begin{array}{l}35-40 \% \text { of passengers who shift their travel times in } \\
\text { the short-run revert to their previous trip schedules in } \\
\text { the long-run. }\end{array}$ \\
\hline $\begin{array}{l}\text { Zou et al. } \\
(2019)\end{array}$ & Beijing, China & $\begin{array}{l}50 \% \text { fare discount on morning pre-peak } \\
\text { trips }\end{array}$ & $\begin{array}{l}\text { Passenger segmentation fol- } \\
\text { lowed by a before-after com- } \\
\text { parison of expected departure } \\
\text { times of passengers in different } \\
\text { segments. }\end{array}$ & $\begin{array}{l}1 \text { month and } 6 \\
\text { months post- } \\
\text { implementation of } \\
\text { the discount }\end{array}$ & $\begin{array}{l}\text { Peak hour ridership decreased approximately by } 2.5 \% \\
\text { in the short-term and } 5 \% \text { in the medium-term. Low- } \\
\text { frequency passengers were found to be more sensitive } \\
\text { to discount fares. }\end{array}$ \\
\hline $\begin{array}{l}\text { Peer et al. } \\
(2016)\end{array}$ & Netherlands & $\begin{array}{l}\text { Travel distance-based monetary re- } \\
\text { wards between } 1.5-4.5 \text { euros for trav- } \\
\text { elling outside peak hours }\end{array}$ & $\begin{array}{l}\text { Before-after comparison of } \\
\text { peak hour trips. }\end{array}$ & $\begin{array}{l}4 \text { months and } \\
6 \text { months post- } \\
\text { implementation } \\
\text { of the rewards } \\
\text { programme }\end{array}$ & $\begin{array}{l}\text { The relative share of peak trips decreased by } 22 \% \text { dur- } \\
\text { ing the reward period, and by } 10 \% \text { during the post- } \\
\text { measurement period, that is, towards the end of the } \\
\text { reward period. }\end{array}$ \\
\hline $\begin{array}{l}\text { Pluntke and } \\
\text { Prabhakar } \\
(2013)\end{array}$ & Singapore MRT & $\begin{array}{l}\text { Rewards program offering commuters } \\
\text { with X and } 3 \mathrm{X} \text { credits for a weekday } \\
\text { trip of X kms in peak and off-peak } \\
\text { hours respectively. }\end{array}$ & $\begin{array}{l}\text { Before-after comparison of fo- } \\
\text { cus group }\end{array}$ & $\begin{array}{l}4 \text { weeks post- } \\
\text { implementation of } \\
\text { the discount }\end{array}$ & $\begin{array}{l}\text { Overall decrease in the percentage of peak trips esti- } \\
\text { mated to be } 7.49 \% \text {. }\end{array}$ \\
\hline Currie (2010) & $\begin{array}{l}\text { Melbourne, } \\
\text { tralia }\end{array}$ & $\begin{array}{l}\text { Free if trips are completed before } 7: 00 \\
\text { a.m. }\end{array}$ & $\begin{array}{l}\text { Before-after comparison of pas- } \\
\text { senger flows. }\end{array}$ & $\begin{array}{l}1 \text { year post- } \\
\text { implementation of } \\
\text { the discount }\end{array}$ & $\begin{array}{l}1.2 \%-1.5 \% \text { reduction in previous level of peak-hour } \\
\text { demand accompanied by high levels of induced de- } \\
\text { mand. }\end{array}$ \\
\hline $\begin{array}{l}\text { McCollom and } \\
\text { Pratt (2004) }\end{array}$ & $\begin{array}{l}\text { Bus systems in Den- } \\
\text { ver, Colorado, and } \\
\text { Trenton, New Jersey }\end{array}$ & $\begin{array}{l}\text { Free inter-peak fares in central busi- } \\
\text { ness districts and universities. }\end{array}$ & $\begin{array}{l}\text { Before-after comparison of pas- } \\
\text { senger flow data. }\end{array}$ & Short-term & $\begin{array}{l}\text { Achieved a reduction in the share of ridership in the } \\
\text { peak to } 30 \% \text { from } 50 \% \text { and to } 55 \% \text { from } 68 \% \text {, in Den- } \\
\text { ver and Trenton respectively. }\end{array}$ \\
\hline
\end{tabular}


Table 2: Factors influencing responsiveness to fare incentive programs.

\begin{tabular}{|c|c|c|}
\hline Factor & Literature & Main Findings \\
\hline Travel Cost & $\begin{array}{l}\text { Henn et al. (2011); Cur- } \\
\text { rie (2010); Maunsell (2007); } \\
\text { Passenger-Focus (2006) }\end{array}$ & $\begin{array}{l}\text { In Melbourne, } 66 \text { percent of passengers with flexible trip schedules during the morn- } \\
\text { ing peak changed their timing of travel to save costs. Commuters making longer } \\
\text { journeys, thus paying higher fares, are more likely to shift even with a simple fare } \\
\text { reduction for the peak shoulders. In the UK, long distance commuters were also } \\
\text { found to have more flexibility in their travel schedules than short distance travellers. }\end{array}$ \\
\hline Scheduled Delay & $\begin{array}{l}\text { Currie (2010); Henn et al. } \\
(2011) ; \quad \text { Passenger-Focus } \\
\text { (2006); Maunsell (2007); } \\
\text { Zhang et al. (2014); Ben-Elia } \\
\text { and Ettema }(2011 a, b, 2009)\end{array}$ & $\begin{array}{l}\text { Commuters with less rigid working schedules made greater shifts in their travel } \\
\text { timing as found in different studies in the UK, Beijing, Sydney, Melbourne and } \\
\text { Netherlands. Interestingly, in most cases, commuters with higher incomes have } \\
\text { been found to have more flexibility in their work schedules, thus suggesting that } \\
\text { these fare incentive policies might be regressive. }\end{array}$ \\
\hline Crowding Costs & $\begin{array}{l}\text { Currie } \quad(2010) ; \quad \text { Maunsell } \\
(2007) ; \\
(2006)\end{array}$ & $\begin{array}{l}\text { Experiencing less crowding in trains when travelling before morning peak, and thus } \\
\text { better quality of service and comfort, has been a major driving force amongst transit } \\
\text { users. On the contrary, some commuters did not prefer to avail such pre-peak travel } \\
\text { fare incentives as they expected the peak hour crowding to reduce post application } \\
\text { of the discount. They expected to enjoy less crowded trains travelling at the same } \\
\text { time or even sometime later during the peak hour. }\end{array}$ \\
\hline $\begin{array}{l}\text { Medium-Term Growth } \\
\text { Effect }\end{array}$ & Passenger-Focus (2006) & $\begin{array}{l}\text { The 'Medium Term Growth Effect' suggests that there exists a time lag between } \\
\text { implementation of any such initiative and obtaining substantial changes in the travel } \\
\text { habits of commuters and thus greater aggregate level impacts. So, an initial ramp } \\
\text { up period is expected and long-term effects are deemed to be greater. }\end{array}$ \\
\hline
\end{tabular}


In recent years, a growing strand of the literature uses large-scale datasets to study the impact of pricing policies (Koutsopoulos et al., 2019). For instance, Halvorsen et al. (2016) conduct a before-after analysis to study the impact of the EBD in Hong Kong using MTR smart card data and find that the EBD had a small impact on demand patterns of MTR users. Ma et al. (2019) extend this study to see how short-term behavioural response to such policies evolve in the long run. They find that 35 to 40 percent of passengers who initially shifted, will eventually revert to their previous trip schedules. Zhu et al. (2019) develop a system based on smart card data to modify an individual's travel behaviour by offering personalised incentives. Other related policy interventions such as the influence of substituting a flat-fare policy with a distance-based fare policy on passenger demand (Wang et al., 2018) have also been studied using smart card data. The main findings from key empirical studies on pre-peak travel discount policies are reported in Table 1.

\subsection{Research Gaps and Contributions}

All previous studies adopt a passenger segmentation approach, followed by a beforeafter comparison of travel patterns of transit users to quantify the effect of a policy intervention. Although analysis of changes in travel behaviour for different commuter and non-commuter groups is important, estimates produced using a simple before-after comparison of travel patterns may not represent the true policy impact. This is because such estimates of the policy impact may be confounded by temporal trends, that is, inherent changes in trip making patterns over time. Other sources of confounding bias are day-to-day changes in weather, seasonality in trip making patterns, and incidents in the network, among many others. Moreover, these studies focus on changes in overall demand, but little is known about the trip rescheduling behaviour of existing users.

Our contribution to this line of research is three-fold.

1. To address the shortcomings of the before-after comparison approach, we adopt an econometrically-sound causal inference method to evaluate the impact of the EBD on trip scheduling behaviour of commuters using Hong Kong MTR. The method accounts for potential sources of confounding bias.

2. We provide highly disaggregate, that is OD-level, causal estimates of the impact of the EBD on trip scheduling. These estimates could be instrumental in the design 
of OD-based control strategies to alleviate crowding levels. As pointed out by Ma and Koutsopoulos (2019), OD-based control strategies perform better than stationbased schemes in targeting passengers that lead to bottlenecks or crowded links in the network.

3. We also derive empirical insights into the factors that determine re-scheduling responsiveness to the EBD. We achieve this by determining the covariates (for instance, travel cost and crowding levels) affecting the heterogeneity in OD-level effects of the EBD.

\section{Methodology and Data}

This section has two main subsections. The first subsection discusses the considered specification of the DID model, followed by the choice of the dependent variable to quantify the rescheduling effect of the EBD. We then discuss our definition of regular commuters and classification of control and treated groups in the DID model. In the second subsection, we summarise relevant details of the smart card data that we use to estimate the effect of the EBD.

\subsection{Method}

\subsubsection{The difference-in-difference regression model}

The analysis is carried out on longitudinal data, comprising $N$ regular commuters indexed with $i=1, \ldots, N$, each of which has $n_{i}$ observations made over times $t, t=1, \ldots, n_{i}$,

giving aggregate of $n=\sum_{(i=1)}^{N} n_{i}$ sample size. Data available for estimation is treated as realisations of a random vector, $Z_{i t}=\left(Y_{i t}, D_{i t}, X_{i t}\right)$, where $Y_{i t}$ denotes a response of interest, $D_{i t}$ the treatment received, and $X_{i t}$ a vector of covariates. In this analysis, the treatment is defined in binary form. The objective is to estimate an average treatment effect (ATE, denoted by $\tau$ ), or in other words, the difference in response that would occur under treatment status $(D=1)$ relative to control status $(D=0)$, averaged over the population (Li et al., 2012).

$$
\tau=E\left[Y_{i t}(1)-Y_{i t}(0)\right]
$$

where $Y_{i t}(1)$ and $Y_{i t}(0)$ are the outcomes for unit $i$ under treatment and control status respectively.

To estimate ATEs, a difference-in-differences (DID) approach is adopted. In the 
simplest DID set-up, sample observations can be classed into one of two treatment groups $D_{i} \in 0,1$ and one of two time periods $t \in 0,1$ (see Section 3.1.3 for details). In time period $t=0$ there are no treated units.

A comparison of post treatment outcome for treated and control units may be subject to problems of confounding, while a comparison of pre and post-treatment outcomes for the treated units may incorporate bias due to temporal trends in the outcome variable or effects of extraneous events that are unrelated to the treatment (see Ashenfelter and Card (1984) and Finkelstein (2002) for detailed discussions). The DID estimator addresses such problems by using information for both treated and control groups in both pre and post treatment periods (Wooldridge, 2010).

In the basic DID model, outcomes $Y_{i t}$ for the observed commuters in binary time periods are modelled using

$$
Y_{i t}=\mu+\alpha I_{D_{i}}+\delta . t+\tau \cdot I_{D_{i}} \cdot t+\varepsilon_{i t}
$$

where $\mu, \alpha, \delta$ and $\tau$ are parameters to be estimated, $I_{D_{i}}$ is an indicator variable representing assignment of the treatment, $I_{D_{i}}=1$ if $D_{i}=1$, zero otherwise, and $\varepsilon_{i t}$ is a potentially autoregressive error with mean zero in each time-period (Wooldridge, 2010). The parameter $\mu$ relates to the expected pre-treatment response of the control group. The parameter $\delta$ measures the difference between the expected post-treatment and pretreatment responses of the control group. The parameter $\alpha$ measures the difference between the expected pre-treatment responses between the treated and control groups. The effect of the treatment is captured by the parameter $\tau$, which provides the sample counterpart to

$$
\tau=\left\{E\left[Y_{i, 1} \mid I_{D_{i}}(1)\right]-E\left[Y_{i, 0} \mid I_{D_{i}}(1)\right]\right\}-\left\{E\left[Y_{i, 1} \mid I_{D_{i}}(0)\right]-E\left[Y_{i, 0} \mid I_{D_{i}}(0)\right]\right\}
$$

with least squares estimate

$$
\hat{\tau}=\left(\overline{Y_{11}}-\overline{Y_{10}}\right)-\left(\overline{Y_{01}}-\overline{Y_{00}}\right)
$$

where $\overline{Y_{11}}$ is the sample average outcome for treated units in the time period when the treatment occurs (Ashenfelter and Card, 1984). 
There are two key identifying assumptions required for the basic DID model. The first assumption follows exogeneity of receipt of the treatment:

$$
\operatorname{Pr}\left(I_{D_{i}} \mid \varepsilon_{i t}\right)=\operatorname{Pr}\left(I_{D_{i}}\right)
$$

for $t=0,1$ (Ashenfelter and Card, 1984). Second, the average outcomes for the treated and control groups are assumed to follow parallel paths over time in the absence of the treatment (Wooldridge, 2010). If $Y_{i t}(0)$ is the outcome that commuter $i$ experiences in time $t$ in the absence of treatment, then the following 'Unconditional Parallel Outcomes' assumption can be made:

$$
E\left[Y_{i, 1}(0)-Y_{i, 0}(0) \mid I_{D_{i}}(1)\right]=E\left[Y_{i, 1}(0)-Y_{i, 0}(0) \mid I_{D_{i}}(0)\right]
$$

For a longitudinal data structure, the basic DID model can be estimated in differences as (Abadie, 2005)

$$
Y_{i, 1}-Y_{i, 0}=\delta+\tau I_{D_{i}}+\left(\varepsilon_{i, 1}-\varepsilon_{i, 0}\right)
$$

Due to absence of micro-level information on commuters, we introduce commuterspecific fixed effects $\gamma_{i}$ in the above equation to capture any unobserved heterogeneity in outcome dynamics between treated and control groups:

$$
Y_{i, 1}-Y_{i, 0}=\delta+\tau I_{D_{i}}+\gamma_{i}+\left(\varepsilon_{i, 1}-\varepsilon_{i, 0}\right)
$$

These fixed effects are identified because a commuter is observed over multiple days pre- and post- treatment. The selected days, over which commuting trips are observed, are discussed in the Section 3.1.3. As the commuter-specific fixed effects create too many parameters, we estimate the model in Equation 3 by time-demeaning the data over different days to eliminate commuter-specific fixed effects. Specifically, we subtract the average response of a commuter $i$ at $t=0$ from each observation at $t=1$ to obtain the dependent variable in Equation $3^{2}$. We estimate this model both at an aggregate level, that is, at the network level and a disaggregate level, that is, at the link level for each

\footnotetext{
${ }^{2}$ Thus, for each commuter $i$, the operation $Y_{i, 1}-\bar{Y}_{i, 0}$ gives a number of observations equal to the number of days the commuter is observed at $t=1$. Through multiple observations on the commuter $i$, we estimate the commuter-specific fixed effects.
} 
discounted OD pair.

We estimate another specification of the DID model at (network) aggregate level to test for heterogeneity in the average treatment effect across OD pairs. In this specification, we allow the treatment effect to vary over observed OD-level travel characteristics $\left(X_{i}\right)$ such as pre-treatment travel cost, pre-treatment crowding and pre-treatment mean exit time $^{3}$ of commuting trips:

$$
Y_{i, 1}-Y_{i, 0}=\delta . X_{i}+\tau_{0} I_{D_{i}}+\tau_{x} I_{D_{i}} \cdot X_{i}+\gamma_{i}+\left(\varepsilon_{i, 1}-\varepsilon_{i, 0}\right) .
$$

The results of this model provide empirical insights into how the effect of the policy varies across OD pairs with different characteristics.

\subsubsection{Dependent variable in the DID model}

We choose arrival time, that is, tap-out time, of regular smart card trips as the response variable $Y_{i t}$ to capture the trip scheduling impact of the EBD. The arrival time is converted into seconds after midnight.

We conduct another analysis by considering the change in departure time as a measure of rescheduling effect. We do not present detailed results of this analysis because the results remain virtually the same at the aggregate (network) level. However, some differences in the statistical significance of the disaggregate (OD-level) estimates are observed. Arrival times of commuters tend to be more concentrated as compared to departure times due to constraints imposed externally by work or other commitments (Small, 1982) and therefore, differences in the statistical significance of corresponding causal effect estimates are expected.

\subsubsection{Selection of control and treated groups}

While recalling that EBD was implemented between 7:15 and 8:15, we use discounted regular-commuting trips terminating in the time window of 7:15 and 9:15 for further analysis. This time window comprises both the discount period and the full peak period. Regular commuters are defined as those MTR users who have regular arrival times in the considered time window during 80 percent of workdays, and travel between the same

\footnotetext{
${ }^{3}$ One may argue that pre-treatment exit time choice might not be an exogenous random variable as it may be confounded by unobserved scheduling constraint of the commuter. We adjust for this confounding bias via inclusion of commuter-specific fixed effects in the DID model.
} 
OD pair in both the pre-treatment and post-treatment periods. We conduct robustness test to check the sensitivity of results relative to the time window and the definition of regular commuters in Section 4.4.

Trips that occur between the same discounted OD pair on 80 percent of workdays jointly in the four months, (1) July 2013, (2) October 2013, (3) July 2014 and (4) October 2014 and terminate in the time window under analysis, are classed into control and treated groups over base and treatment years as follows:

1. Time period $t=0$, that is, base year;

Control: Regular commuting trips in the given time window in July 2013,

Treated: Regular commuting trips in the given time window in October 2013.

2. Time period $t=1$, that is, treatment year;

Control: Regular commuting trips in the given time window in July 2014,

Treated: Regular commuting trips in the given time window in October 2014.

We discuss the rationale behind these choices. We consider that the date of implementation of the EBD, that is September 1, 2014, is chosen exogenously. We select regular commuting trips terminating in the considered time window from a month post- and pre-implementation of the policy as our treated and control groups respectively. We have the data on trips taken on the MTR network from July 2013 to October 2013 and from July 2014 to October 2014. We thus have two available choices for the control group July and August. We find that our results are consistent across both choices. Therefore, for brevity, we present results with July as the control group. We again have two choices for the treated group - September and October. The literature suggests the initial month of implementation of such policies marks a period of transition in the travel behaviour of users (Passenger-Focus, 2006). Therefore, we select October as the treated group to study the short-term effect of the EBD.

We now conduct a descriptive analysis of treated and control groups. Figure 2 shows the distribution of arrival times for all regular commuting trips between the discounted OD pairs in the considered time window on all workdays in July and October in 2013 $(t=0)$ and $2014(t=1)$. The corresponding summary statistics are reported in Table 3 and box-plots are illustrated in Figure 3. Both figure and table show similar distributions and moments of arrival times in the control (July) and treated (October) groups in the base year (2013), which suggests that the parallel trend assumption is satisfied. 


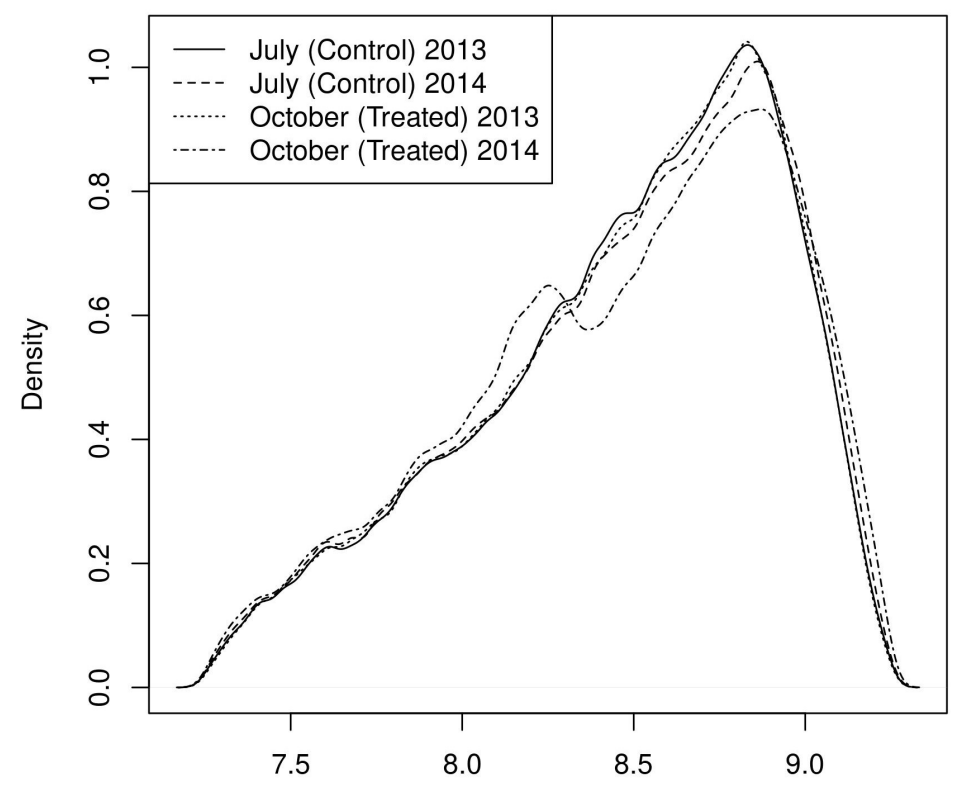

Figure 2: Kernel density plots for arrival times of regular commuting trips between the discounted OD pairs during 07:15 to 09:15.

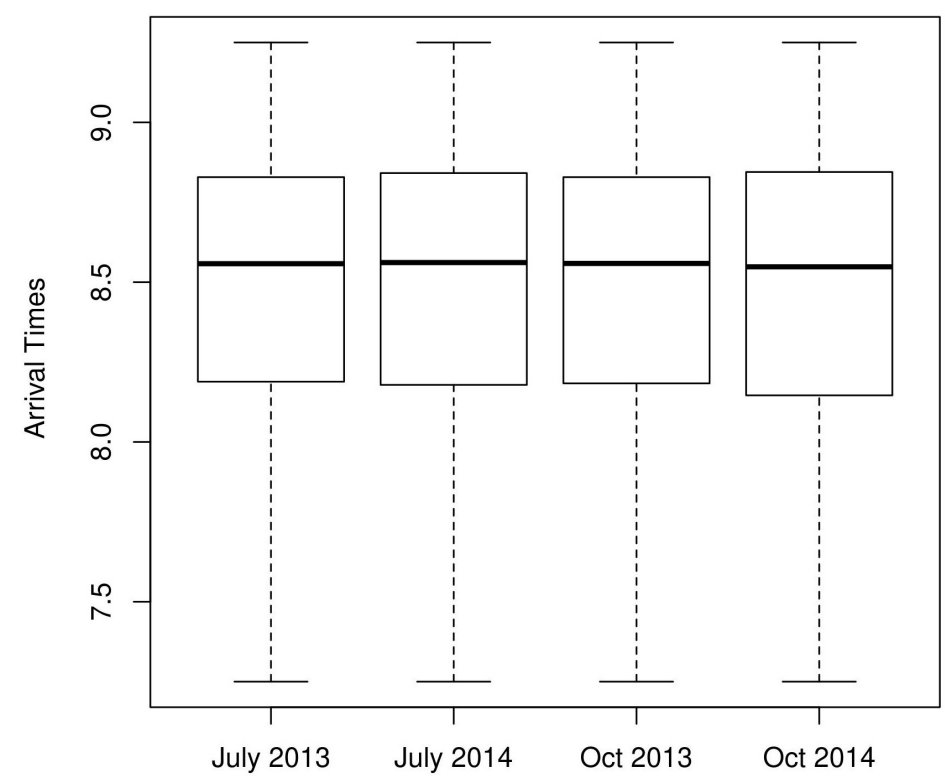

Figure 3: Box plots for arrival times of regular commuting trips between the discounted OD pairs in the time window 07:15 to 09:15 by treatment group and year.

Table 3: Summary statistics for arrival times of regular commuting trips between the discounted OD pairs in the time window 07:15 to 09:15 by treatment group and year.

\begin{tabular}{lccccc}
\hline treatment group & year & no. of obs. & mean arrival time & std. dev. (in secs) & median \\
\hline treated (October) & 2013 & 873591 & $08: 28: 34$ & 26.58 & $08: 33: 41$ \\
control (July) & 2013 & 909497 & $08: 28: 37$ & 26.57 & $08: 33: 28$ \\
treated (October) & 2014 & 811006 & $08: 28: 05$ & 27.74 & $08: 32: 53$ \\
control (July) & 2014 & 873591 & $08: 28: 44$ & 27.06 & $08: 33: 31$ \\
\hline
\end{tabular}


The results also indicate that the distribution and moments of arrival times do not differ substantially for the control and treated groups in 2013 and 2014. This descriptive analysis suggests that the magnitude of the impact of the EBD is likely to be small. We draw similar observations when we do the above analysis at OD-level ${ }^{4}$. Therefore, a detailed empirical analysis is important to understand the trip rescheduling effect of the EBD.

\subsection{Data}

\subsubsection{Context}

In 2014, the Mass Transit Railway (MTR) in Hong Kong was the world's ninth busiest metro system with an annual ridership of 1.8 billion trips. Most of the MTR lines were operating at their capacities during the morning peak. With the aim to mitigate the overcrowding situation during the morning peak, the Early Bird Discount (EBD) was introduced by the MTR on the 1st of September 2014. It allows MTR users to avail a 25 percent fare incentive if they exit at the twenty-nine designated stations as shown in Figure 4 between 07:15 to 08:15.

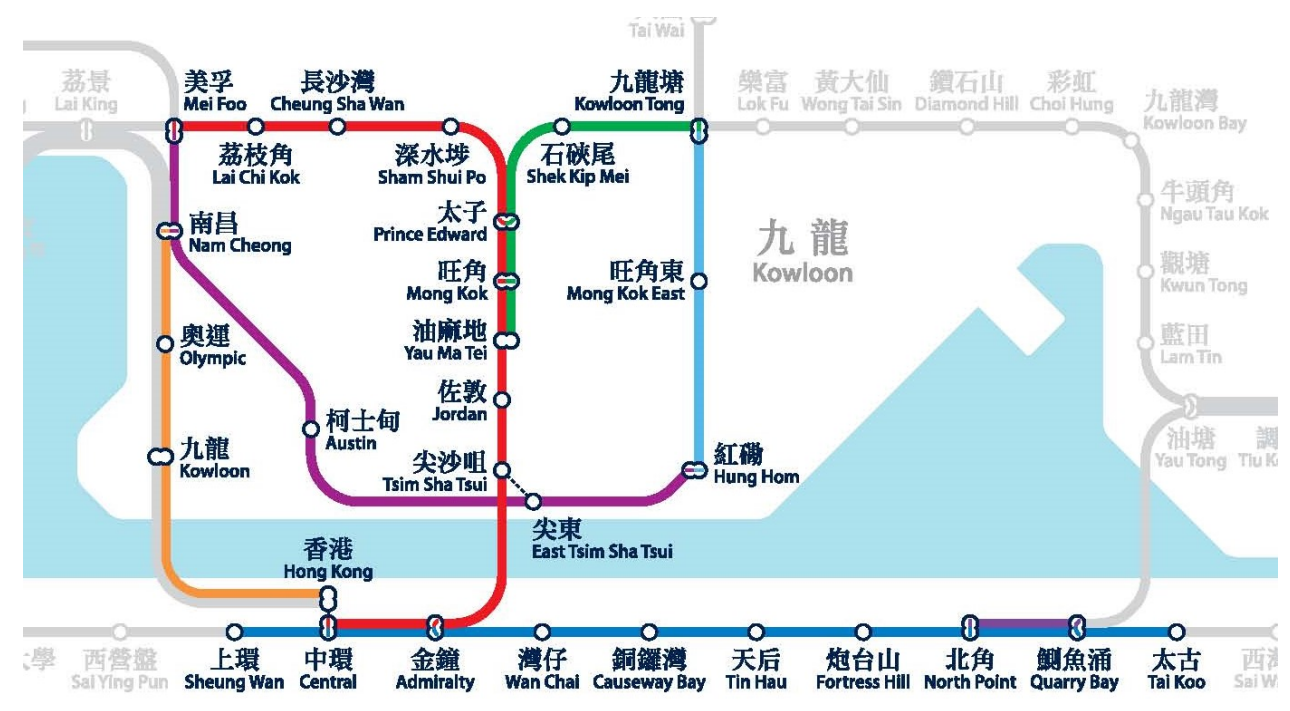

Figure 4: The MTR network map showing the 29 inner-city stations covered under the EBD.

Before implementation of the EBD the operator predicted that on average, 105 thousand users would benefit from the EBD daily and 5000 to 7000 users per day would shift

\footnotetext{
${ }^{4}$ Given a large number of discounted OD pairs (around 1700), we do not report comparisons for each OD pair.
} 
from peak hours. In addition, the operator expected the shift of 2.5 to 3.5 percent of users from the critical peak hour (08:15 to 09:15).

\subsubsection{Smart card data}

We use smart card data provided by Hong Kong MTR to analyse the impact of the EBD. The MTR dataset is unique in the sense that unlike most metros around the world it is a closed system. All stations in the MTR network are fenced and thus the smart card data record all trips performed in the network. It contains information about transactions at both the origin and destination stations. The data contain record for millions of smart card transactions occurring in the MTR network over the study period. The attributes include card number (ID), card type (e.g. student, senior traveller and disabled), transaction date, time, station code, Octopus card balance, and the fare paid during the actual trip. Fares on the MTR network are based on distance with higher costs to travel further. As of June 2014, adult Octopus fares ranged from HK\$3.5 HK\$27.6 for most OD pairs, with cross-harbour trips costing more due to an accompanied surcharge. Travel to or from one of the HK border crossing stations is also higher, with fares starting from $\mathrm{HK} \$ 22.4$.

\section{Results and Discussion}

This section has four subsections. The first subsection summarises the main implications of the aggregate (network-level) and disaggregate (OD-level) DID estimates. The second subsection further investigates the distribution of the OD-level DID estimates and their spatial distribution is presented in the third subsection. The final subsection tests the sensitivity of DID estimates by i) considering narrower sub-intervals of the original time window (07:15 to 09:15), and ii) varying the 80-percent selection criterion for regular commuting trips.

\subsection{Main results}

Table 4 summarises results of the DID analysis with and without fixed effects. We first discuss aggregate (network-level) DID estimates. A statistically significant reduction in the arrival times of regular commuting trips terminating between 7:15 and 9:15 is evident, but the magnitude of the reduction is small ( $\sim 25$ seconds) for both specifications. Whereas the magnitude of DID estimate from the model with commuter-specific fixed 
effects is similar to the one without them, the standard error of the estimate with fixed effects is much lower. This observation suggests that we are indeed able to capture an additional portion of unobserved heterogeneity by incorporating fixed effects. Consequently, the DID model with commuter fixed effects is our preferred specification.

Table 4: The main results of the DID analysis.

\begin{tabular}{lcc}
\hline Model Specification & Without FE & With FE \\
\hline Percent peak hour trips analysed & 11.44 & 11.44 \\
Mean Exit Time prior to the & $08: 28: 25$ & $08: 28: 25$ \\
treatment & & \\
Aggregate DID estimate (in secs) & $\mathbf{- 2 6 . 1 6}$ & $\mathbf{- 2 4 . 6 4}$ \\
& $\mathbf{( 1 . 0 8 )}$ & $\mathbf{( 0 . 8 0 )}$ \\
Number of OD pairs analysed & 1704 & 1704 \\
No. of OD pairs with estimates & 839 & 995 \\
$\begin{array}{l}\text { significant at the 95 percent level } \\
\text { No. of OD pairs with (significant) }\end{array}$ & 513 & 595 \\
$\begin{array}{l}\text { negative estimates } \\
\text { Percent OD pairs with (significant) } \\
\text { negative estimates }\end{array}$ & $\mathbf{3 0 . 1}$ & $\mathbf{3 4 . 9}$ \\
\hline
\end{tabular}

Note: numbers in parenthesis denote the standard errors associated with the estimates.

The disaggregate (OD-level) analysis suggests that the impact of the EBD is limited to a sub-section of the population and there exists heterogeneity in response patterns. We observe that only 995 OD pairs out of 1704 discounted OD pairs, that is 58.4 percent, show statistically significant change in arrival times post-EBD at the 95 percent confidence level. Moreover, only 595 OD pairs, that is 34.9 percent of total, show statistically significant reduction in arrival times post-EBD.

We analyse 11.44 percent of the total peak hour trips in the time window from 07:15 to $09: 15 .^{5}$ Out of these trips, 43.48 percent of trips are associated with 595 OD pairs that show a statistically significant reduction in arrival times due to the EBD. However, given that the pre-treatment mean arrival time of trips on the MTR network is around 08:28 and the aggregate reduction in arrival times post-treatment is just around 25 seconds, the net decrease in peak hour trips seems to be very small.

This result is consistent with the literature in Table 1 which suggests that the effect

\footnotetext{
${ }^{5}$ Note that the share of regular commuters appears to be small. This is because MTR does not provide its users with an option to register their smart cards and therefore, MTR commuters are less inclined to use the same card over the years. However, we can safely ignore the possibilities of selection bias because there is no reason for commuters to have this tendency in a systematic way. Our robustness test in Section 4.4.2 further validates this hypothesis.
} 
of similar levels of discounts on peak hour demand is small and ranges between 3 to 5 percent. Although, it is worth re-emphasising that the effects estimated in this study are solely due to rescheduling of existing commuters, while the literature reports the overall impact on the peak hour demand, which includes the effects of induced demand.

\subsection{Detailed analysis of disaggregate-level DID estimates}

We further analyse the OD-level DID estimates in detail. One may argue that insignificance of a OD-level DID estimate can be due to low number of observations (that is, commuting trips) for that OD pair. To investigate this hypothesis, we plot the distribution of analysed and significant OD estimates over the percent share of regular commuting trips between an OD pair in Figure 5. From this figure, we note that significant effects are not limited to OD pairs with a large share of commuting trips. A considerable proportion of analysed OD pairs with lower ridership shares have statistically significant effect associated with the EBD. This trend suggests that insignificant effect of the EBD on an OD pair is not systematically associated with ridership numbers.

We also visualise the distribution of the significant OD-level DID estimates over changes in arrival times of regular commuting trips in Figure 6. This figure shows that change in arrival time for most of the OD pairs ranges from reduction of 20 minutes to increment by 15 minutes.

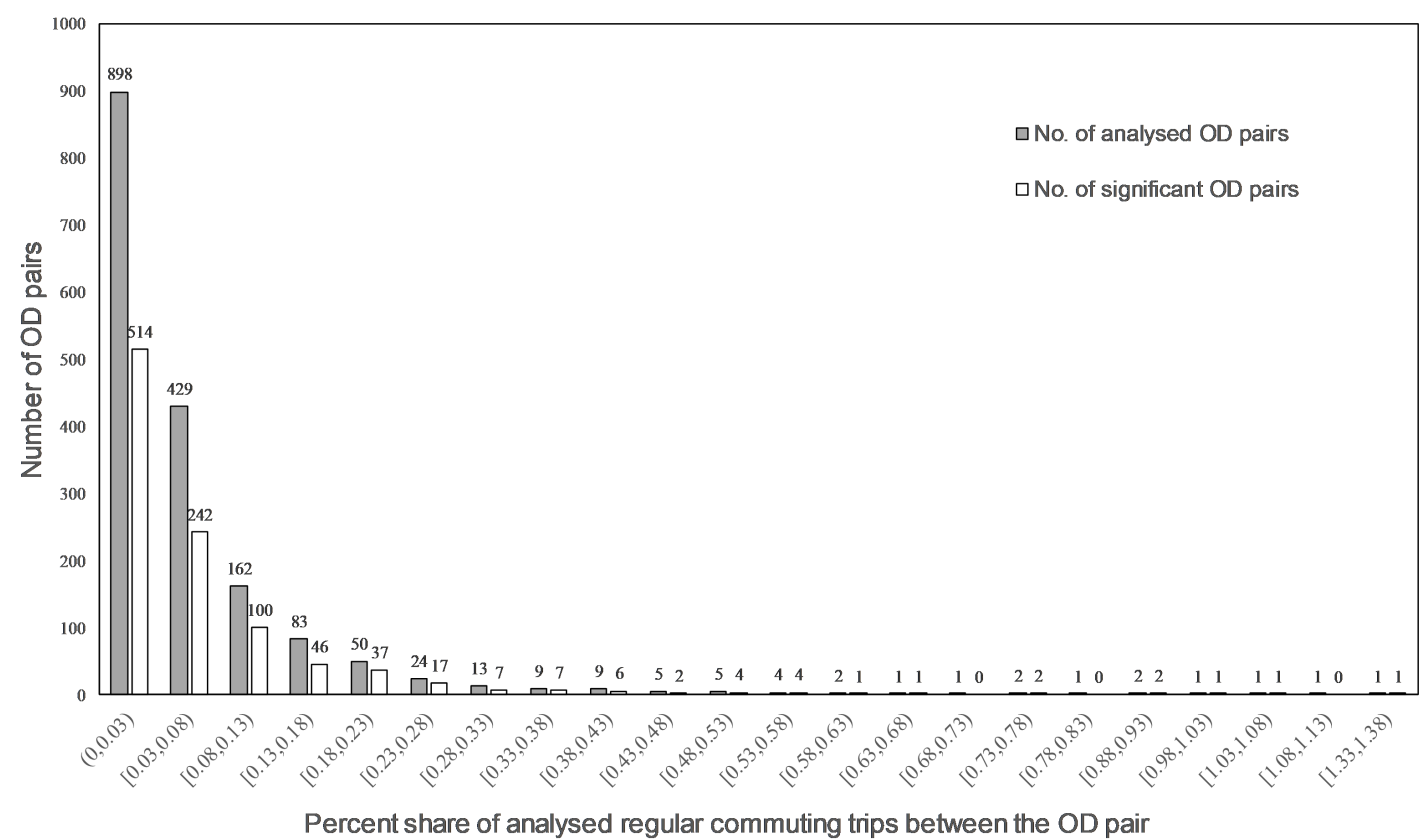

Figure 5: Distribution of number of analysed and significant OD pairs in the time window 07:15 to $09: 15$ over the share of regular commuting trips between each OD pair. 


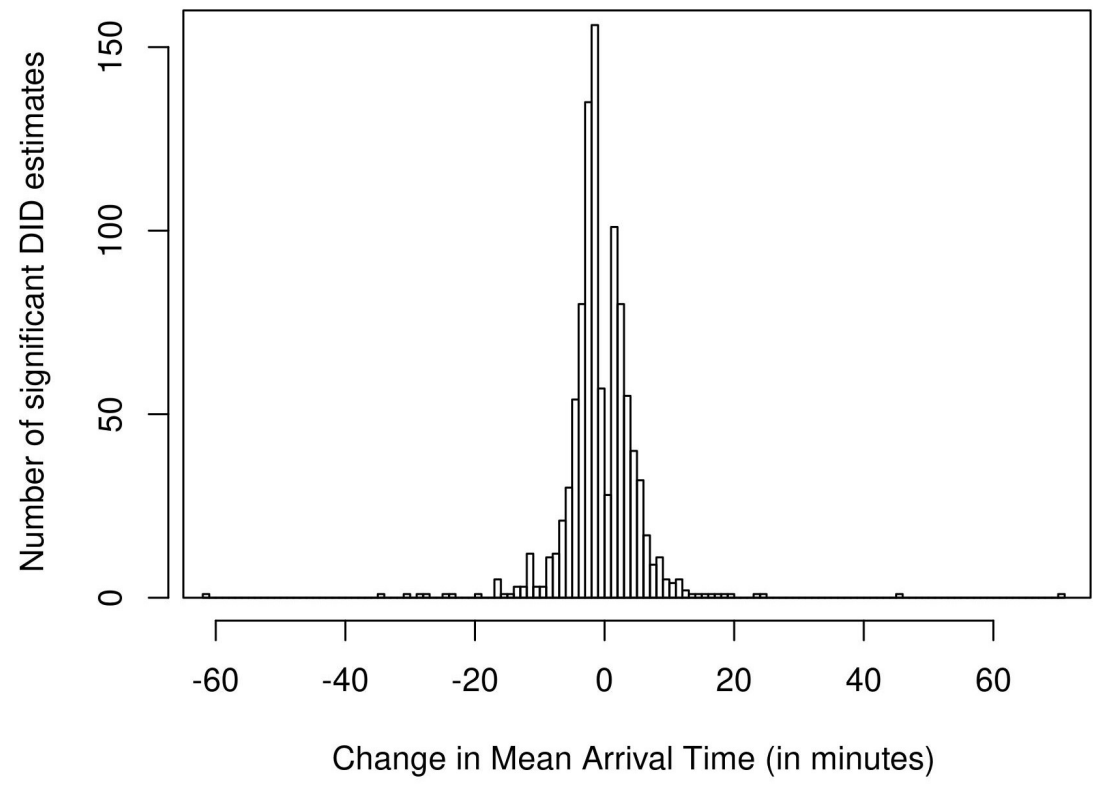

Figure 6: Distribution of the significant OD-level DID estimates for the time window 07:15 to 09:15 over the observed change in arrival time.

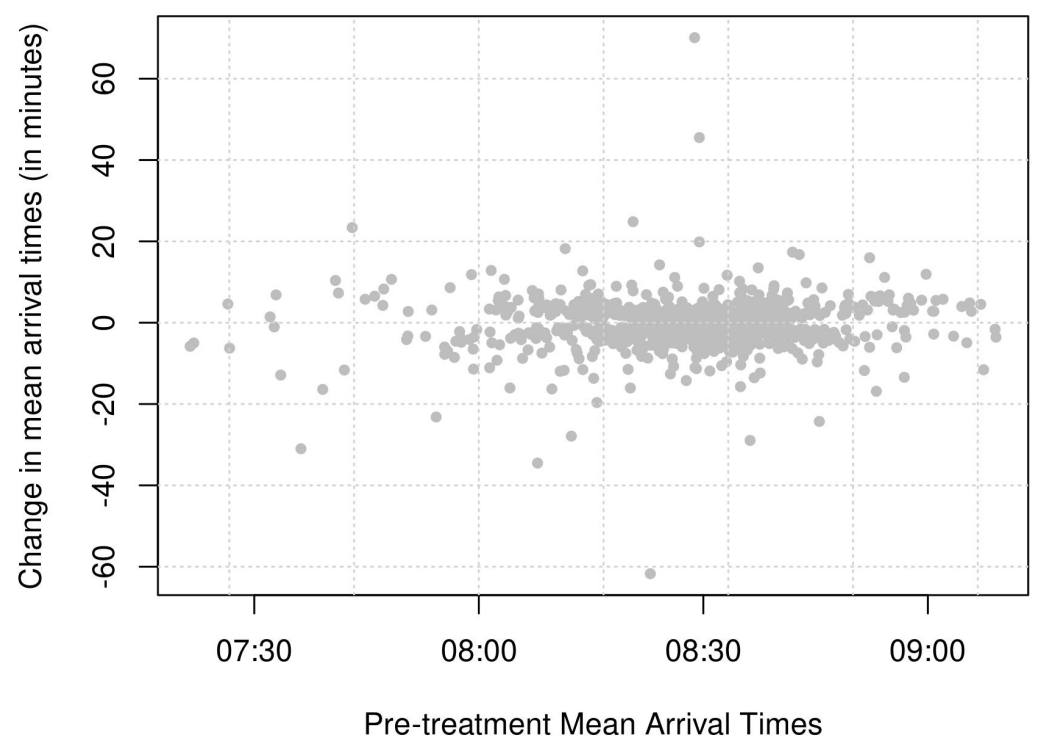

Figure 7: Variation of the significant OD-level DID estimates for the time window 07:15 to 09:15 with the pre-treatment arrival times.

Also, Figure 7 shows that the OD pairs with pre-treatment mean arrival times in the interval of 08:10 to 08:40 feature the highest concentration of significant DID estimates. This observation suggests that the impact of the policy is more pronounced at the start of the peak, that is between 08:15 and 08:40. Its effect during the more critical peak-of-the- 
peak, that is 08:45 to 09:15, seems to be low. Many treated OD pairs with pre-treatment mean arrival times greater than 08:15 show positive shifts, which implies that regular commuters travelling on these OD pairs try to reschedule their trips from the pre-peak discounting period to the peak period (Figure 7). Some of the previous studies observed similar response patterns (see the discussion on Crowding Cost in Table 2). A potential explanation for the positive shifts is that certain passenger groups might have expected intensifying crowding by the end of the discount period, and reduction in peak crowding after the application of the policy.

\subsection{Spatial distribution of the rescheduling effect}

Figures 8 and 9 show the spatial distribution of the impact of the EBD on arrival and departure times of regular commuting trips terminating in the time window 07:15 to 09:15. Figure 8 shows that some of destinations on the East Rail line and the West Rail line either do not show any statistically significant changes in arrival times of trips or the magnitude of changes observed is small, even though they fall in the discounted zone. We also note that all the destinations situated in Hong Kong Island show significant impact. These are the destinations that are associated with higher crowding levels. Based on this observation, we can say that the policy seems to have a desired impact in terms of targeting more crowded destinations in the network.

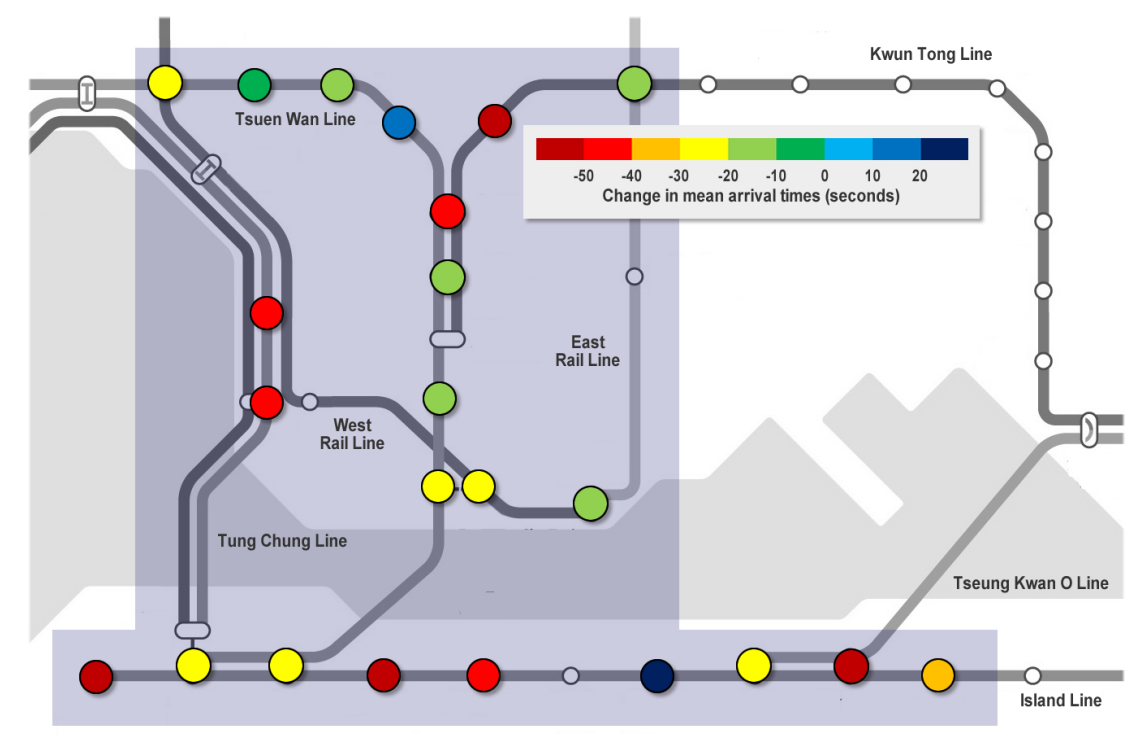

Figure 8: Spatial variation of changes in mean arrival times of regular commuting trips terminating in the time window 07:15 to 09:15 over discounted destinations. 


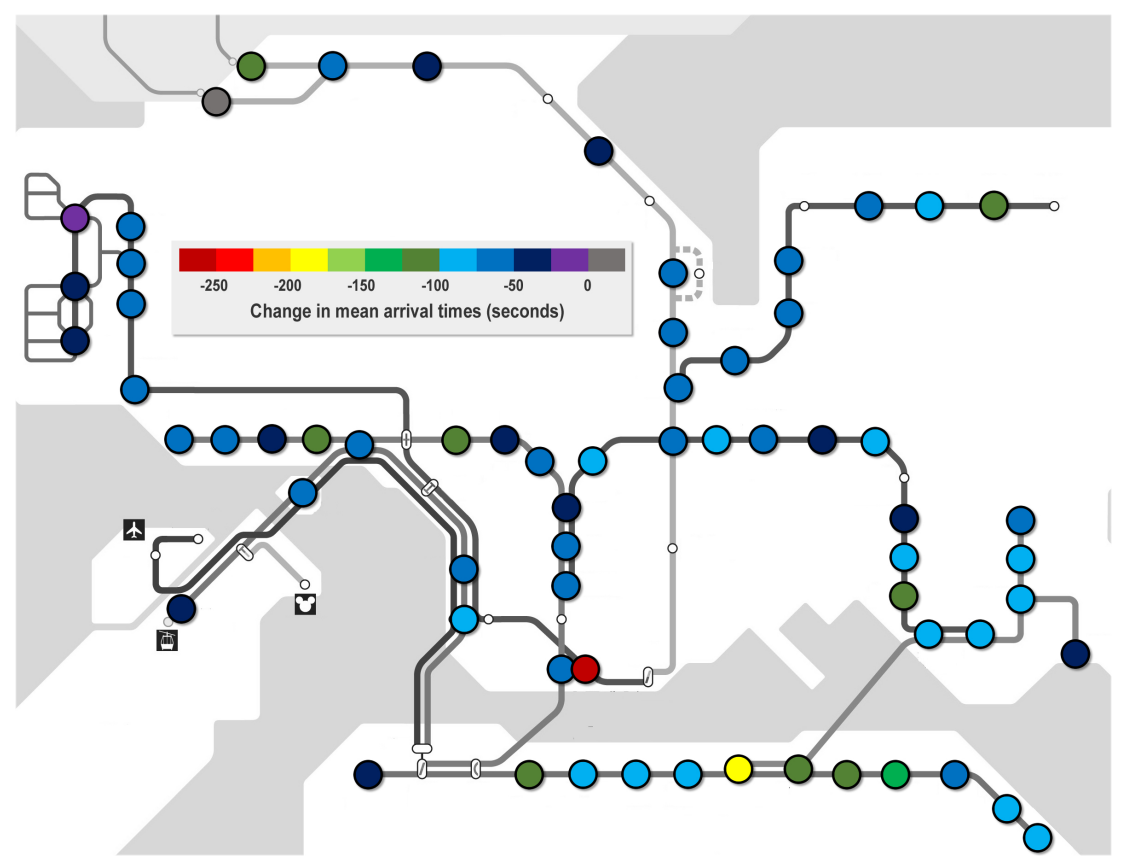

Figure 9: Spatial variation of changes in mean departure times of regular commuting trips terminating in the time window 07:15 to 09:15 over all origins.

Figure 9 shows that origin stations that are located within the discounted zone are associated with larger magnitude of reduction in departure times. As noted previously, these stations are amongst the most crowded stations in the network. Therefore, once again we conclude that the policy seems to achieve its aim of targeting more crowded links in the network.

\subsection{Robustness Tests}

In this section, we test the robustness of the DID estimates relative to i) the time window, and ii) the selection criterion to filter out regular commuters. We consider a DID specification with commuter-specific fixed effects in both robustness tests.

\subsubsection{Time window}

We capture the sensitivity of results relative to the time window by analysing three sub-intervals of the original time window (07:15 to 09:15) in which discounted regularcommuting trips terminate:

1. 07:30 to 09:00 (45 minutes around 08:15),

2. 07:45 to 08:45 (30 minutes around 08:15),

3. 08:00 to 08:30 (15 minutes around 08:15), 
where $08: 15$ is the end of the discount period. Table 5 summarises the DID estimates for all time windows.

Table 5: Summary of DID estimates for different time windows.

\begin{tabular}{lcccc}
\hline Analysed time interval & $07: 15$ to & $07: 30$ to & $07: 45$ to & $08: 00$ to \\
& $09: 15$ & $09: 00$ & $08: 45$ & $08: 30$ \\
\hline Percent peak hour trips analysed & 11.4 & 10.4 & 8.3 & 4.9 \\
Mean Exit Time prior to treatment & $08: 28: 25$ & $08: 23: 41$ & $08: 17: 47$ & $08: 15: 17$ \\
Aggregate DID estimate (in secs) & $\mathbf{- 2 4 . 6 4}$ & $\mathbf{- 4 0 . 0 6}$ & $\mathbf{- 5 6 . 2 1}$ & $\mathbf{- 5 9 . 1 5}$ \\
& $(0.80)$ & $(0.84)$ & $(0.95)$ & $(1.25)$ \\
& 1704 & 1604 & 1453 & 1034 \\
Number of OD pairs analysed & 58.4 & 57.4 & 60.3 & 58.6 \\
$\begin{array}{l}\text { Percent OD pairs with significant } \\
\text { estimates at the 95 percent level }\end{array}$ & $\mathbf{3 4 . 9}$ & $\mathbf{3 7 . 2}$ & $\mathbf{4 1 . 4}$ & $\mathbf{4 3 . 6}$ \\
$\begin{array}{l}\text { Percent OD pairs with negative } \\
\text { (significant) estimates }\end{array}$ & 63.8 & 65.1 & 66.9 & $\mathbf{6 5 . 4}$ \\
$\begin{array}{l}\text { Total trip share comprised by OD } \\
\text { pairs with significant estimates }\end{array}$ & & & & \\
Total trip share comprised by OD & 43.5 & 49.1 & 53.7 & 53.4 \\
pairs with negative estimates & & & & \\
\hline
\end{tabular}

Note: (i) Numbers in parenthesis denote the standard errors associated with the estimates.

(ii) All model specifications include commuter-specific fixed-effects.

We observe that narrower is the time window, higher is the magnitude of the aggregate DID estimate, that is, more is the aggregate reduction in arrival times post-EBD. This increase in response implies that the commuting trips which terminate closer to the end of the discounting period before implementation of EBD, show higher flexibility in changing their arrival times to avail the discount.

With respect to the OD-level DID analysis in other time windows, we find 57.4 percent, 60.3 percent and 58.6 percent of the analysed OD pairs with statistically significant DID estimates for time windows 07:30 to 09:00, 07:45 to 08:45 and 08:00 to 08:30 respectively. Furthermore, 37.2 percent, 41.4 percent and 43.6 percent of the analysed OD pairs show statistically significant reduction in mean arrival times post-treatment, respectively, for these three intervals. These estimates, along with trip shares, are consistent with those of the original time window (07:15 to 09:15).

\subsubsection{Selection criterion for regular commuters}

We are aware that the criterion that we use to select regular commuters can potentially lead to biased estimates of the impact of the EBD. We could have directly dealt with this challenge using an instrumental variable approach if smart card data were available for 
multiple years. In the absence of such data set, we carry out robustness checks to test the sensitivity of our DID estimates relative to the selection criterion used to filter out regular commuters.

We vary the selection criterion to filter out trips that have regular arrival times in the time window 07:15 to 09:15 on (1) 70 percent, (2) 80 percent and (3) 90 percent of workdays, and travel between the same discounted OD pair in both the pre-EBD and post-EBD periods. Table 6 summarises results of this analysis. We find that the results are fairly robust, that is, the aggregate change in arrival times do not vary substantially with the change in the selection criterion. The results of the robustness test thus suggest that selection bias is not a major concern in this study.

Table 6: Sensitivity of results relative to the selection criterion for regular commuters.

\begin{tabular}{lccc}
\hline Selection Criterion & 70 percent & 80 percent & 90 percent \\
\hline Percent peak hour trips analysed & 17.7 & 11.4 & 2.9 \\
Mean Exit Time prior to the treatment & $08: 28: 25$ & $08: 28: 50$ & $08: 24: 23$ \\
Aggregate DID estimate (in secs) & $\mathbf{- 2 8 . 5 6}$ & $\mathbf{- 2 4 . 6 4}$ & $\mathbf{- 2 4 . 0 9}$ \\
& $(0.69)$ & $(0.80)$ & $(1.48)$ \\
& 1802 & 1704 & 1272 \\
Number of OD pairs analysed & 1022 & 995 & 723 \\
$\begin{array}{l}\text { No. of OD pairs with significant } \\
\text { estimates at the 95 percent level }\end{array}$ & 630 & 595 & 410 \\
$\begin{array}{l}\text { No. of OD pairs with (significant) } \\
\text { negative estimates }\end{array}$ & & & \\
$\begin{array}{l}\text { Percent OD pairs with (significant) } \\
\text { negative estimates }\end{array}$ & $\mathbf{3 5 . 0}$ & $\mathbf{3 4 . 9}$ & $\mathbf{3 2 . 2}$ \\
\hline
\end{tabular}

Note: (i) Numbers in parenthesis denote the standard errors associated with the estimates.

(ii) All model specifications include commuter-specific fixed-effects.

\section{Factors influencing responsiveness to the EBD}

Although the aggregate level impact estimated in this analysis is small, varying OD-level DID estimates suggest that there is heterogeneity in response patterns. We explore this variation by allowing the aggregate treatment effect to vary over observed OD-level pre-treatment covariates in another specification of the DID model (as specified in equation 4). In the next sub-section, we discuss the covariates in this DID model followed by a discussion of the results from estimation of this model.

\subsection{Covariates}

We use travel characteristics like pre-treatment travel cost and average pre-treatment arrival timing for trips that are obtained from smart card data. Average pre-treatment OD-level 
crowding densities are obtained by matching smart card data with train movement data using the methodology detailed in Hörcher et al. (2017). Table 7 provides the summary statistics of these covariates.

The DID model with heterogeneous treatment effects requires to satisfy the overlap condition at each level of the covariates (Hainmueller et al., 2019). ${ }^{6}$ However, testing this assumption at the entire joint support of continuous covariates is infeasible. Therefore, we divide each continuous covariate into three equally-spaced bins and test this assumption in each bin of the joint support of all covariates. With one binary and three continuous covariates, we end up with $54\left(2 \times 3^{3}\right)$ bins. The overlap condition is satisfied in all 54 bins of the joint support, however for brevity, we only present these results for the marginal support of each continuous covariate in the Appendix.

Table 7: Summary statistics of covariates in the DID model with heterogeneous treatment effects.

\begin{tabular}{|c|c|c|c|c|c|c|}
\hline Variable & Obs. & Min & Max & Median & Mean & Std.Dev \\
\hline $\begin{array}{l}\text { Pre-treatment Mean Exit } \\
\text { Time (in minutes) from } \\
\text { 8:15 A.M. }\end{array}$ & 1704 & -53.57 & 54.10 & 13.73 & 12.43 & 14.54 \\
\hline $\begin{array}{l}\text { Average Crowding Density } \\
\text { (passenger } / \mathrm{m} 2 \text { ) }\end{array}$ & 1704 & 0.01 & 5.26 & 1.53 & 1.76 & 1.10 \\
\hline Harbour Crossing Dummy & 1704 & 0.00 & 1.00 & 0.00 & 0.40 & 0.49 \\
\hline Travel Cost $(\mathrm{HK} \$)$ & 1704 & 3.65 & 46.10 & 9.06 & 9.57 & 4.87 \\
\hline
\end{tabular}

*Legend: Obs.: Observations, Std. Dev.: Standard Deviation.

\subsection{Results}

Table 8 summarises results of the DID model with heterogeneous treatment effect for the time window 07:15 to 09:15. We discuss results in the subsequent subsection.

\subsubsection{Mean exit time from the end of discount period}

We find that OD pairs with higher pre-treatment mean arrival times are systematically associated with more positive average treatment effects. A minute increase in average pretreatment arrival times brings about a 0.14 second increase in the average treatment effect. This increase reinforces our explanation for the counter-trend positive shifts discussed in Section 4.2. We argued that certain passenger groups may have expected intensifying crowding by the end of the discount period, and reduction in peak crowding due to the policy. This perception is

\footnotetext{
${ }^{6}$ We also check the non-linearity of multiplicative interaction effects, but did not find any supporting evidence.
} 
Table 8: Summary of Results from the DID model with heterogeneous treatment effects.

\begin{tabular}{lrr}
\hline Explanatory Variable & Coefficient & Std.Error \\
\hline Average Treatment Effect (ATE) & $-16.89^{* * *}$ & 2.41 \\
Pre-treatment Mean Exit Time (in & $0.14^{* * *}$ & 0.03 \\
minutes) from 8:15 A.M. x ATE & & \\
Average Crowding Density & $3.05^{* * *}$ & 0.73 \\
(passenger/m2) x ATE & & \\
Travel Cost (HK $\$$ ) x ATE & $-0.96^{* * *}$ & 0.24 \\
Harbour Crossing Dummy x ATE & $-19.44^{* * *}$ & 1.87 \\
\hline Number of observations & 1720976 & \\
\hline
\end{tabular}

Note: (i) Significance: $\left({ }^{* *}\right) 99$ percent, $\left({ }^{* *}\right) 95$ percent, $\left({ }^{*}\right) 90$ percent.

(ii) The model specification includes commuter-specific fixed effects.

more likely to affect those OD pairs where the pre-treatment mean arrival time was already relatively late before the intervention.

\subsubsection{Average Crowding Density}

We find that OD pairs with higher pre-treatment crowding levels are associated with more positive average treatment effects. A unit increase in average crowding density, expressed in passengers per squared metres, leads to an increase of about 3 seconds in the average treatment effect. Thus, once again, we find that the expectation for reduced peak-hour crowding levels and a more comfortable travel due to the discount may cause passenger groups to travel more in the peak as opposed to availing the monetary benefit due to the discount.

\subsubsection{Travel Cost}

We find that savings in travel cost is a key factor in motivating the commuters to avail the discount. A unit increase in travel cost leads to a decrease of about 1 second in the average treatment effect.

\subsubsection{Harbour Crossing Dummy}

The harbour crossing dummy variable, set equal to 1 in case of cross-harbour commuting trips and 0 otherwise, has a significant effect on the average treatment effect. Cross-harbour trips involve a fare surcharge and have higher crowding densities during peak hours. The mean arrival time of cross-harbour trips is reduced by 19 seconds more compared to trips not involving harbour crossing. Since cross-harbour trips involve a fare surcharge, monetary travel cost savings could be a major factor determining response to the EBD. Expectation for lower crowding levels could be an additional incentive for cross-harbour commuters to shift their travel timing, although new demand induced by the discount policy itself may partly neutralise this 
benefit. As concluded previously in Section 4.3, the policy seems to have the desired impact in terms of targeting more crowded links in the network.

\section{Conclusions}

This paper evaluates the impact of the Early Bird Discount (EBD) policy on the trip scheduling preferences of regular MTR commuters in Hong Kong via application of an appropriate causal inference approach (that is, the difference-in-differences method) to smart card data. The DID analysis suggests that overall, there has been a very small, although statistically significant, reduction in mean arrival times of regular commuting trips due to the EBD. The aggregate reduction shown by discounted regular commuting trips is only 25 seconds. Thus, it seems that fare discounts of 25 percent have little impact on rescheduling behaviour and peak-hour crowding within the first two months of implementation. The rescheduling of trips is found to be more intensive for trips with pre-treatment mean arrival times closer to $08: 15$, that is the end of the discounting period. In other words, the policy had a local trip rescheduling effect in the proximity of the end of the discount period. Thus, the policy had achieved little success targeting the peak-of-the-peak in the short run. These results are consistent with previous studies which suggest that similar levels of pre-peak travel discounts in cities like Melbourne and London have had a very limited effect on peak crowding.

As the impact of the such policies is limited to peak shoulders, the policy should be arguably modified if the operator's aim is to target the peak-of-the-peak. A simple fare incentive of 25 percent does not seem strong enough to incentivise commuters to shift their travel timing by 30 minutes or more. As the rescheduling response was not uniform throughout the discounting period, a fares policy that is more differentiated may be more effective in curbing demand in the most crowded period. Specifically, a policy with variable or tapered discounts throughout the shoulder peak period, that is, greater discounts for trips terminating much before the peak period as compared to those terminating very close to the peak period, accompanied with peakof-the peak surcharges might significantly affect trip scheduling preferences. The caveat is that a differentiated fare policy may be perceived by users as a profit-maximising solution ${ }^{7}$. However, in practice, it may not be the case if regulators set a constraint such as maximum returns on asset base (RAB regulation) or a profit cap, or if a basket of fares acts as the price cap around which fares can vary temporally and spatially. From the operator's perspective, none of these

\footnotetext{
${ }^{7}$ Note that De Palma et al. (2017) derive that the social optimal uniform fare leads to the same aggregate demand and consumer surplus as the socially optimal dynamic tariff schedule: "Introducing differentiated fares creates a welfare gain without making users worse off. Looked at another way, it allows the operator to boost farebox revenues without reducing ridership."
} 
would be difficult to implement. A future way around the inequity of peak of peak fares could be to price by route. Any changes would need to be considered in the context of the overall financial sustainability of the metro. This means adjusting the pricing as well as subsidy levels to ensure sufficient funds for reinvestment and renewal sustainability.

The granularity of smart card data also allows us to estimate the heterogeneity in response patterns observed for different origin-destination pairs, stations and lines of the network. Identification of such disaggregate-level causal effects facilitate the implementation of OD-based strategies, as recommended in Ma and Koutsopoulos (2019), to target critical links in the network and achieve both performance improvement and cost-efficiency. Furthermore, the DID framework also provides us with a powerful tool to understand the factors determining the observed response. Such factors were identified in the past via travel surveys. Monetary costs and crowding costs are found to be the significant factors, thus providing supporting evidence for previous studies. Such results could help the operator identify non-respondent user groups and then target these groups with more detailed information on crowding relief benefits and travel cost savings to aid them in scheduling their trips. This could help increase the impact of such policies and make them more effective in spreading peak hour ridership.

Through this research, we contribute with novel aggregate and disaggregate level causal estimates of trip rescheduling elasticities of MTR commuters. As mentioned in the Introduction, differential pricing has an impact on both (i) the aggregate trip volume, and (ii) the scheduling behaviour of individuals. The economic literature of pricing in public transport, including Huang (2000), Kraus and Yoshida (2002), De Palma et al. (2015) and a recent contribution by De Palma et al. (2017), suggest that the optimal dynamic fare scheme is determined by the marginal social cost of travelling in various points in time. Note that the computation of marginal social costs and the determination of whether the policy in its current form has lead to a welfare improving departure from the original tariff system, will require a full analysis of the changes in demand. However, the novel empirical evidence on trip scheduling elasticities delivered by this paper can be utilised to calibrate theoretical models in the aforementioned literature. In particular, scheduling elasticities can be used as part of future research to infer the preferred arrival time pattern of morning commuters, which is a missing input parameter in dynamic pricing studies such as De Palma et al. (2017). This empirical contribution paves the way to the practical applicability of existing theoretical models.

It is worth noting that this study only quantifies the short-term impact of the EBD on arrival time preferences of commuters. However, in the long run, changes in public transport systems may affect the urban structure via affecting house prices, wages, housing supply and 
labour demand and may also impact car ownership, housing prices and wages (Mulalic and Rouwendal, 2020; Heblich et al., 2020). Thus, quantifying the long-term causal impact of the EBD is a potential direction of future research, which would enable transit operators to estimate whether the commuters are entirely unresponsive to price changes or they are simply slow to adjust. Moreover, the long-term effect of such policies on the induced demand can also be pursued in future as it would help in assessing whether the operators should consider the capacity increment or not. We aim to analyse these long-run impacts of the EBD within a causal inference framework in our future work.

\section{Acknowledgement}

We are grateful to the two anonymous reviewers from Transportation Research Part A: Policy and Practice whose comments and suggestions helped us substantially improve the quality of this paper. 


\section{References}

Abadie, A. (2005), 'Semiparametric difference-in-differences estimators', The Review of Economic Studies $\mathbf{7 2 ( 1 ) , 1 - 1 9 .}$

Agard, B., Morency, C. and Trépanier, M. (2006), 'Mining public transport user behaviour from smart card data', IFAC Proceedings Volumes 39(3), 399-404.

Ashenfelter, O. C. and Card, D. (1984), 'Using the longitudinal structure of earnings to estimate the effect of training programs', Review of Economics and Statistics 67(4), 648-660.

Bagchi, M. and White, P. R. (2005), 'The potential of public transport smart card data', Transport Policy 12(5), 464-474.

Ben-Elia, E. and Ettema, D. (2009), 'Carrots versus sticks: Rewarding commuters for avoiding the rush-hour - a study of willingness to participate', Transport Policy 16(2), 68-76.

Ben-Elia, E. and Ettema, D. (2011a), 'Changing commuters' behavior using rewards: A study of rush-hour avoidance', Transportation research part F: traffic psychology and behaviour 14(5), 354-368.

Ben-Elia, E. and Ettema, D. (2011b), 'Rewarding rush-hour avoidance: A study of commuters' travel behavior', Transportation Research Part A: Policy and Practice 45(7), 567-582.

Currie, G. (2010), 'Quick and effective solution to rail overcrowding: free early bird ticket experience in Melbourne, Australia', Transportation Research Record: Journal of the Transportation Research Board (2146), 35-42.

De Palma, A., Kilani, M. and Proost, S. (2015), 'Discomfort in mass transit and its implication for scheduling and pricing', Transportation Research Part B: Methodological 71, 1-18.

De Palma, A., Lindsey, R. and Monchambert, G. (2017), 'The economics of crowding in rail transit', Journal of Urban Economics 101, 106-122.

Finkelstein, A. (2002), 'The effect of tax subsidies to employer-provided supplementary health insurance: evidence from Canada', Journal of Public Economics 84(3), 305-339.

Goulet-Langlois, G., Koutsopoulos, H. N. and Zhao, J. (2016), 'Inferring patterns in the multiweek activity sequences of public transport users', Transportation Research Part C: Emerging Technologies 64, 1-16. ID: 271729. 
Graham, D. J., Crotte, A. and Anderson, R. J. (2009), 'A dynamic panel analysis of urban metro demand', Transportation Research Part E: Logistics and Transportation Review 45(5), 787794.

Hainmueller, J., Mummolo, J. and Xu, Y. (2019), 'How much should we trust estimates from multiplicative interaction models? simple tools to improve empirical practice', Political Analysis 27(2), 163-192.

Halvorsen, A. A. F. (2015), Improving transit demand management with Smart Card data: general framework and applications, $\mathrm{PhD}$ thesis, Massachusetts Institute of Technology.

Halvorsen, A., Koutsopoulos, H. N., Lau, S., Au, T. and Zhao, J. (2016), 'Reducing subway crowding: Analysis of an off-peak discount experiment in Hong Kong', Transportation Research Record: Journal of the Transportation Research Board (2544), 38-46.

Halvorsen, A., Koutsopoulos, H. N., Ma, Z. and Zhao, J. (2019), 'Demand management of congested public transport systems: a conceptual framework and application using smart card data', Transportation pp. 1-29.

Heblich, S., Redding, S. J. and Sturm, D. M. (2020), 'The making of the modern metropolis: Evidence from London', The Quarterly Journal of Economics .

Henn, L., Douglas, N. and Sloan, K. (2011), 'Surveying Sydney rail commuters' willingness to change travel time', Conference Proceedings, 34th Australasian Transport Research Forum Conference, Adelaide, Australia .

Henn, L., Karpouzis, G. and Sloan, K. (2010), 'A review of policy and economic instruments for peak demand management in commuter rail', Conference Proceedings, 33rd Australasian Transport Research Forum Conference, Canberra .

Huang, H.-J. (2000), 'Fares and tolls in a competitive system with transit and highway: the case with two groups of commuters', Transportation Research Part E 36(4), 267-284.

Hörcher, D., Graham, D. J. and Anderson, R. J. (2017), 'Crowding cost estimation with large scale smart card and vehicle location data', Transportation Research Part B: Methodological 95, 105-125.

Koutsopoulos, H. N., Ma, Z., Noursalehi, P. and Zhu, Y. (2019), Transit data analytics for planning, monitoring, control, and information, Mobility Patterns, Big Data and Transport Analytics, Elsevier, pp. 229-261. 
Kraus, M. and Yoshida, Y. (2002), 'The commuter's time-of-use decision and optimal pricing and service in urban mass transit', Journal of Urban Economics 51(1), 170-195.

Li, H., Graham, D. J. and Majumdar, A. (2012), 'The effects of congestion charging on road traffic casualties: A causal analysis using difference-in-difference estimation', Accident Analysis E Prevention 49, 366-377.

Liu, Y. and Charles, P. (2013), 'Spreading peak demand for urban rail transit through differential fare policy: a review of empirical evidence', In Australasian Transport Research Forum 2013 Proceedings. .

Long, Y. and Thill, J.-C. (2015), 'Combining smart card data and household travel survey to analyze jobs-housing relationships in Beijing', Computers, Environment and Urban Systems 53, 19-35.

Ma, Z., Basu, A. A., Liu, T. and Koutsopoulos, H. N. (2019), 'Behavioral response to transit demand management promotions: Sustainability and implications for optimal promotion design', TRID Record No. 19-05266 .

Ma, Z. and Koutsopoulos, H. N. (2019), 'Optimal design of promotion based demand management strategies in urban rail systems', Transportation Research Part C: Emerging Technologies 109, 155-173.

Maunsell, F. (2007), Demand management techniques-peak spreading, Technical report, Report for Department for Transport, Transport for London and Network Rail, London, United Kingdom.

McCollom, B. E. and Pratt, R. H. (2004), Traveller Response to Transportation System Changes. Chapter 12-Transit Pricing and Fares, number Project B-12A FY'99.

Mulalic, I. and Rouwendal, J. (2020), 'Does improving public transport decrease car ownership? evidence from a residential sorting model for the copenhagen metropolitan area', Transportation Research Part B: Methodological 83.

Passenger-Focus (2006), Encouraging edge of morning peak travel: Research findings and policy considerations, Technical report, Passenger Focus, Warrington, UK.

Paulley, N., Balcombe, R., Mackett, R., Titheridge, H., Preston, J., Wardman, M., Shires, J. and White, P. (2006), 'The demand for public transport: The effects of fares, quality of service, income and car ownership', Transport Policy 13(4), 295-306. 
Peer, S., Knockaert, J. and Verhoef, E. T. (2016), 'Train commuters' scheduling preferences: Evidence from a large-scale peak avoidance experiment', Transportation Research Part B: Methodological 83, 314-333.

Pluntke, C. and Prabhakar, B. (2013), 'INSINC: a platform for managing peak demand in public transit', JOURNEYS, Land Transport Authority Academy of Singapore pp. 31-39.

Preston, J., Wall, G., Batley, R., Ibáñez, J. N. and Shires, J. (2009), 'Impact of delays on passenger train services: evidence from Great Britain', Transportation Research Record: Journal of the Transportation Research Board (2117), 14-23.

Small, K. A. (1982), 'The scheduling of consumer activities: work trips', The American Economic Review 72(3), 467-479.

Wang, Y., de Almeida Correia, G. H., van Arem, B. and Timmermans, H. H. (2018), 'Understanding travellers' preferences for different types of trip destination based on mobile internet usage data', Transportation Research Part C: Emerging Technologies 90, 247-259.

Wardman, M. (2014), 'Price elasticities of surface travel demand a meta-analysis of UK evidence', Journal of Transport Economics and Policy 48(3), 367-384.

Whelan, G. and Johnson, D. (2004), 'Modelling the impact of alternative fare structures on train overcrowding', International Journal of Transport Management 2(1), 51-58.

Wooldridge, J. M. (2010), Econometric analysis of cross section and panel data, MIT press.

Zhang, Z., Fujii, H. and Managi, S. (2014), 'How does commuting behavior change due to incentives? an empirical study of the Beijing subway system', Transportation Research Part F: Traffic Psychology and Behaviour 24, 17-26.

Zhu, X., Wang, F., Chen, C. and Reed, D. D. (2019), 'Personalized incentives for promoting sustainable travel behaviors', Transportation Research Part C: Emerging Technologies .

Zou, Q., Yao, X., Zhao, P., Wang, Z. and Yang, T. (2019), 'Measuring retiming responses of passengers to a prepeak discount fare by tracing smart card data: A practical experiment in the Beijing subway', Journal of Advanced Transportation 2019. 


\section{Appendix}

In this section, we present different kernel density plots and summary statistics to test the parallel trend assumption at different levels of covariates that are included DID model with the heterogeneous treatment effects (refer equation 4).

(a) Less than 1.75 pax/sqm.

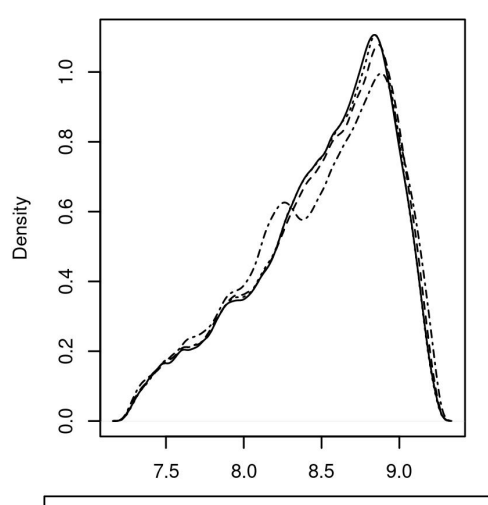

(b) 1.75 to $3.5 \mathrm{pax} / \mathrm{sqm}$.

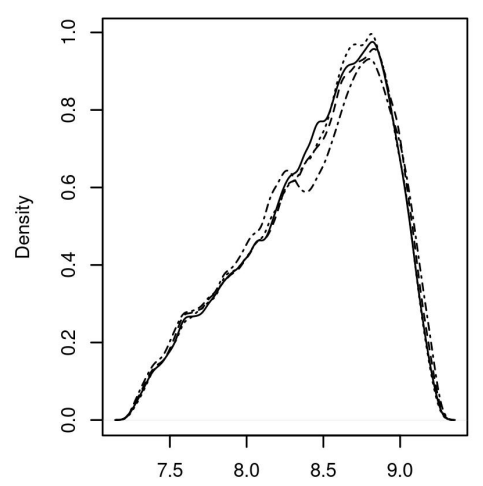

(c) More than 3.5 pax/sqm.

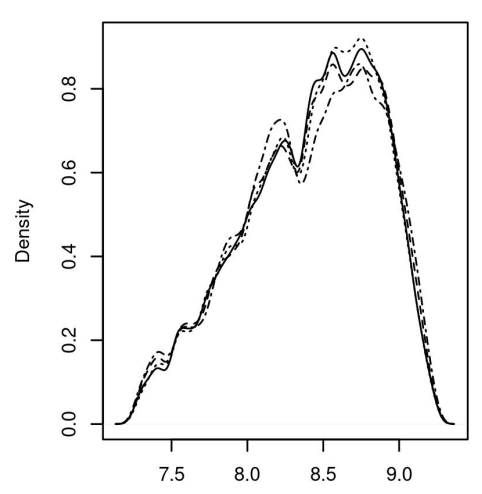

— Untreated (July) $2013 \quad$--- $\quad$ Treated (July) $2014 \quad$ …. $\quad$ Untreated (October) $2013 \quad$-.-.- $\quad$ Treated (October) 2014

Figure 10: Kernel Density Plots for OD pairs with indicated levels of average pre-treatment crowding densities (in passengers per metre square).

(a) Less than 15 HK\$.

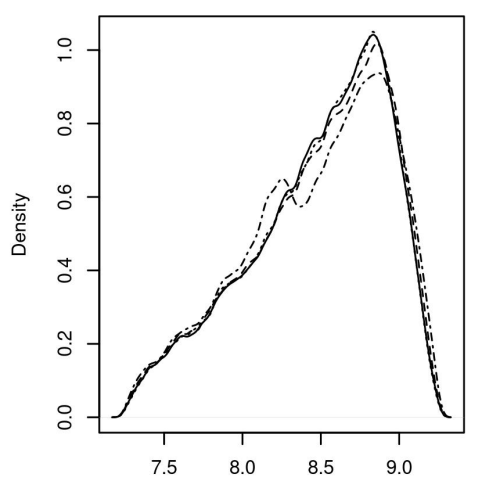

(b) Between 15 to $30 \mathrm{HK} \$$.

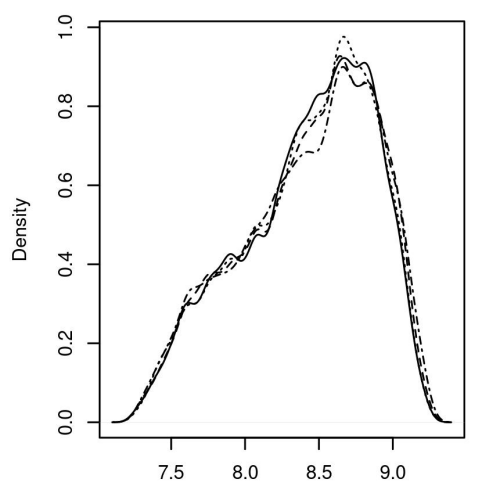

(c) \{More than 30 HK\$.

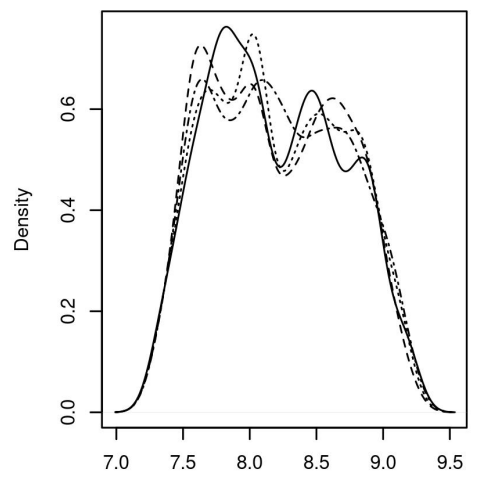

— Untreated (July) $2013 \quad$ - - - $\quad$ Treated (July) $2014 \quad$ …. $\quad$ Untreated (October) $2013 \quad$..... $\quad$ Treated (October) 2014

Figure 11: Kernel Density Plots for OD pairs with indicated levels of pre-treatment travel costs. 
(a) Less than -20 minutes.

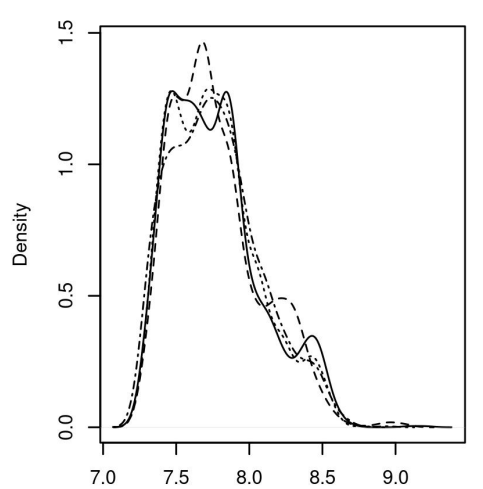

(b) Between-20 to 20 minutes.

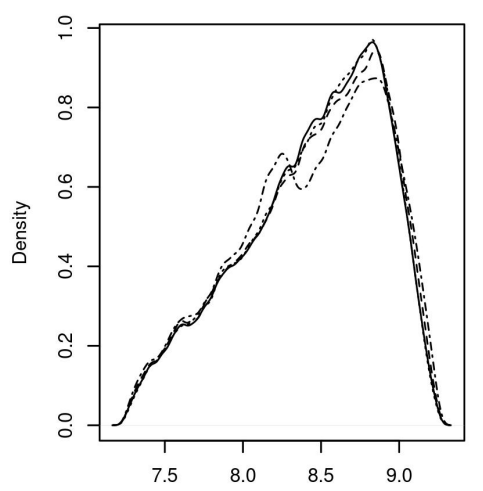

(c) More than 20 minutes.

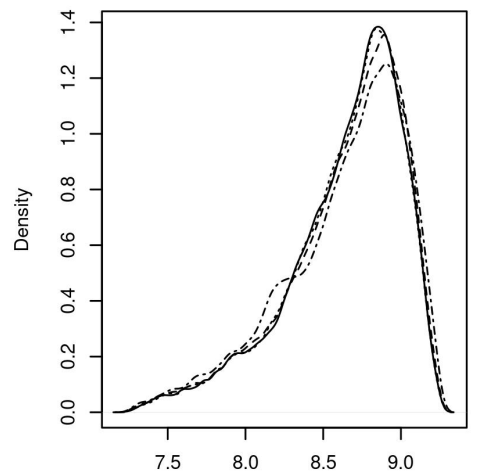

— Untreated (July) 2013 _-- $\quad$ Treated (July) 2014

….. Untreated (October) 2013

Treated (October) 2014

Figure 12: Kernel Density Plots for OD pairs with indicated levels of pre-treatment mean arrival times (from 08:15).

\begin{tabular}{lccc}
\hline treatment group & year & mean arrival time & std. dev. (in secs) \\
\hline treated (October) & 2013 & $08: 30: 11$ & 26.41 \\
untreated (July) & 2013 & $08: 30: 18$ & 26.87 \\
treated (October) & 2014 & $08: 30: 00$ & 26.47 \\
untreated (July) & 2014 & $08: 29: 31$ & 27.66 \\
\hline
\end{tabular}

(a) Less than 1.75 pax per sqm.

\begin{tabular}{lccc}
\hline treatment group & year & mean arrival time & std. dev. (in secs) \\
\hline treated (October) & 2013 & $08: 27: 07$ & 26.74 \\
untreated (July) & 2013 & $08: 27: 22$ & 27.26 \\
treated (October) & 2014 & $08: 27: 14$ & 26.70 \\
untreated (July) & 2014 & $08: 26: 46$ & 27.88 \\
\hline
\end{tabular}

(b) Between 1.75 to 3.5 pax per sqm.

\begin{tabular}{lccc}
\hline treatment group & year & mean arrival time & std. dev. (in secs) \\
\hline treated (October) & 2013 & $08: 25: 12$ & 26.38 \\
untreated (July) & 2013 & $08: 25: 05$ & 26.96 \\
treated (October) & 2014 & $08: 25: 16$ & 26.36 \\
untreated (July) & 2014 & $08: 24: 50$ & 27.36 \\
\hline
\end{tabular}

(c) More than 1.75 to 3.5 pax per sqm.

Table 9: Mean and standard deviation of average arrival times of regular commuting trips between the discounted OD pairs with the indicated levels of pre-treatment average crowding densities (in passengers per metre square). 


\begin{tabular}{lccc}
\hline treatment group & year & mean arrival time & std. dev. (in secs) \\
\hline treated (October) & 2013 & $08: 28: 48$ & 26.53 \\
untreated (July) & 2013 & $08: 28: 55$ & 27.03 \\
treated (October) & 2014 & $08: 28: 44$ & 26.54 \\
untreated (July) & 2014 & $08: 28: 12$ & 27.72 \\
\hline
\end{tabular}

(a) Less than 15 HK\$.

\begin{tabular}{lccc}
\hline treatment group & year & mean arrival time & std. dev. (in secs) \\
\hline treated (October) & 2013 & $08: 25: 08$ & 26.57 \\
untreated (July) & 2013 & $08: 25: 37$ & 27.11 \\
treated (October) & 2014 & $08: 25: 08$ & 26.70 \\
untreated (July) & 2014 & $08: 25: 30$ & 27.72 \\
\hline
\end{tabular}

(b) Between $15 \mathrm{HK} \$$ to $30 \mathrm{HK}$.

\begin{tabular}{lccc}
\hline treatment group & year & mean arrival time & std. dev. (in secs) \\
\hline treated (October) & 2013 & $08: 11: 46$ & 29.53 \\
untreated (July) & 2013 & $08: 11: 24$ & 29.90 \\
treated (October) & 2014 & $08: 12: 40$ & 29.78 \\
untreated (July) & 2014 & $08: 12: 36$ & 29.97 \\
\hline
\end{tabular}

(c) More than $30 \mathrm{HK} \$$.

Table 10: Mean and standard deviation of average arrival times of regular commuting trips between the discounted OD pairs with the indicated levels of pre-treatment travel costs.

\begin{tabular}{lccc}
\hline treatment group & year & mean arrival time & std. dev. (in secs) \\
\hline treated (October) & 2013 & $07: 46: 12$ & 18.82 \\
untreated (July) & 2013 & $07: 46: 26$ & 18.49 \\
treated (October) & 2014 & $07: 45: 43$ & 17.86 \\
untreated (July) & 2014 & $07: 46: 08$ & 18.50 \\
\hline
\end{tabular}

(a) Less than -20 minutes.

\begin{tabular}{lccc}
\hline treatment group & year & mean arrival time & std. dev. (in secs) \\
\hline treated (October) & 2013 & $08: 26: 35$ & 26.88 \\
untreated (July) & 2013 & $08: 26: 46$ & 27.38 \\
treated (October) & 2014 & $08: 26: 35$ & 26.89 \\
untreated (July) & 2014 & $08: 26: 06$ & 27.98 \\
\hline
\end{tabular}

(b) Between -20 minutes to 20 minutes.

\begin{tabular}{lccc}
\hline treatment group & year & mean arrival time & std. dev. (in secs) \\
\hline treated (October) & 2013 & $08: 38: 31$ & 22.23 \\
untreated (July) & 2013 & $08: 38: 31$ & 22.80 \\
treated (October) & 2014 & $08: 38: 24$ & 22.25 \\
untreated (July) & 2014 & $08: 37: 55$ & 23.93 \\
\hline
\end{tabular}

(c) More than 20 minutes.

Table 11: Mean and standard deviation of average arrival times of regular commuting trips between the discounted OD pairs with the indicated levels of pre-treatment mean arrival times. 